\title{
Modelagem do transporte de cloreto proveniente de esgoto urbano em um aquífero sedimentar usando MT3D: o caso da bateria de poços de Juazeiro do Norte (CE)
}

\author{
Modeling of transport of chloride in a sedimentary aquifer using MT3D: \\ the case of a well field in Juazeiro do Norte (CE)

\begin{abstract}
Manoel Roberval Pimentel Santos', Maria Marlucia Freitas Santiago², Luiz Alberto Ribeiro Mendonça ${ }^{3}$, Horst Frischkorn ${ }^{4}$, Josué Mendes Filho ${ }^{5}$
\end{abstract}

\begin{abstract}
RESUMO
Esse trabalho consiste em um estudo de caso, em que o modelo de transporte de soluto MT3D, associado ao modelo de fluxo MODFLOW, foi utilizado na avaliação da contaminação de um aquífero por água superficial de um riacho contaminado com esgoto urbano, utilizando o cloreto como traçador. Nessa área, as águas do aquífero são explotadas por uma bateria de poços alinhada ao riacho. A calibração do modelo de transporte foi executada para reproduzir os teores de cloretos observados nas águas dos poços em campanhas de monitoramento. Já a do modelo de fluxo procurou reproduzir as cargas hidráulicas observadas durante testes de bombeamentos realizados em cada poço. Os resultados obtidos nessas calibrações foram compatíveis com as observações. A partir dos modelos calibrados, foi realizada uma simulação futura (prognóstico), visando determinar o tempo necessário para a recuperação da qualidade de água subterrânea após interrupção do lançamento de esgoto no riacho. Os resultados da modelagem indicaram que: os rebaixamentos produzidos pelo bombeamento dos poços são maiores nas proximidades do riacho; o transporte de contaminante ocorre, predominantemente, na vertical, induzido pelo bombeamento dos poços e pela recarga do aquífero a partir do riacho; os níveis de cloretos relativamente elevados nas águas dos poços podem voltar aos valores naturais do aquífero em aproximadamente um ano, caso o lançamento de esgoto no riacho seja interrompido. Assim, para evitar um maior comprometimento dos aquíferos da área por poluição persistente, o esgoto deverá ter um destino adequado e a área de preservação permanente do riacho deverá ser respeitada.
\end{abstract}

Palavras-chave: águas subterrâneas; transporte de poluentes; MODFLOW, MT3D.

\begin{abstract}
This paper presents a case study in which the solute transport model MT3D, associated with the MODFLOW flow model, was used in the assessment of contamination of an aquifer by surface water from a creek contaminated with urban wastewater, using chloride as a tracer In that area of the aquifer, groundwater is exploited through a field of wells along the creek. The calibration of the transport model was implemented in order to reproduce the levels of chloride in water from wells observed in monitoring campaigns. The flow model sought to reproduce the hydraulic loads observed during pumping tests conducted in each well. The results obtained from these calibrations were consistent with observations. Based on the calibrated models, we carried out a "future simulation" (prognosis), in order to determine the time required for recovery of groundwater quality after stopping sewage discharge into the creek. Modeling results indicate that: drawdowns produced by pumping the wells are higher in the proximity of the creek; contaminant transport occurs, predominantly, vertically induced by pumping of the wells and by aquifer recharge from the creek; elevated levels of chloride in the waters from the wells may return to natural values in about one year, if the release of sewage into the creek is stopped. In this context, in order to prevent further damage to the aquifer area through persistent pollution, sewage must have a suitable destination and the area of permanent protection of the creek must be respected.
\end{abstract}

Keywords: groundwater; transport of polluting; MODFLOW; MT3D.

Doutor em Física. Professor Adjunto do Programa de Física Ambiental da Universidade Federal do Oeste do Pará (UFOPA) - Santarém (PA), Brasil.

${ }^{2}$ Doutora em Ciências. Professora Associada do Departamento de Física da Universidade Federal do Ceará (UFC) - Fortaleza (CE), Brasil.

${ }^{3}$ Doutor em Engenharia Civil. Professor Adjunto do Curso de Engenharia Civil da UFC - Fortaleza (CE), Brasil.

${ }^{4}$ Doutor em Física. Professor Associado do Departamento de Engenharia Hidráulica e Ambiental da UFC - Fortaleza (CE), Brasil.

${ }^{5}$ Doutor em Física. Professor Titular do Departamento de Física da UFC - Fortaleza (CE), Brasil.

Endereço para correspondência: Maria Marlucia Freitas Santiago - Campus do Pici, Departamento de Física. Caixa Postal 6030 - $60455-900$ - Fortaleza (CE), Brasil -

E-mail:marlucia@fisica.ufc.br

Recebido: 31/10/12 - Aceito: 07/01/14 - Reg. ABES: 698 


\section{INTRODUÇÃO}

A preocupação com os problemas relacionados à contaminação de aquíferos, devido às mais diversas fontes de contaminantes, tem levado muitos pesquisadores a estudar os processos físicos, químicos e biológicos associados, bem como formular métodos analíticos e numéricos para a solução das equações que governam o transporte de poluentes. Esses estudos levaram ao desenvolvimento de modelos matemáticos que simulam o comportamento dos sistemas aquíferos em presença de contaminação. Esses modelos podem ser constituídos de equações diferenciais ordinárias de fácil solução analítica até equações diferenciais parciais não lineares que só podem ser resolvidas por métodos numéricos (SALCEDO-SÁNCHEZ et al., 2013).

Existem aplicativos computacionais que fornecem soluções numéricas para modelos que simulam o transporte de contaminantes em meio poroso. Nesse aspecto, a aplicabilidade de cada modelo depende tanto das características do sistema aquífero, quanto do tipo de contaminante que é avaliado. Um dos modelos tridimensionais de transporte de massa existentes é o MT3D (ZHENG, 1990; ZHENG \& GORELICK, 2003). Esse modelo possui uma estrutura modular que permite a simulação de processos de transporte, interagindo diretamente com o modelo de fluxo MODFLOW (MCDONALD \& HARBAUGH, 1988). Nele, a equação diferencial parcial que descreve o transporte tridimensional de soluto de uma única espécie em aquíferos é resolvida utilizando o método implícito das diferenças finitas.

Antes do desenvolvimento do MT3D existia um grande número de modelos analíticos bidimensionais (WILSON \& MILLER, 1978; LINDSTROM \& BOERSMA, 1989) e tridimensionais (HUYAKORN et al., 1987; BATU, 1996; LEIJ; SKAGGS; VAN GENUCHTEN, 1991) de transporte de soluto em aquíferos, no entanto, a maioria deles baseava-se na suposição do meio poroso infinito.

Após o desenvolvimento do MT3D, surgiu o MT3DMS, que simula o transporte tridimensional de soluto multiespécie, também com estrutura modular (ZHENG, 2009 e 2010) e interface com o MODFLOW. Esses dois modelos numéricos de transporte tridimensional recentemente desenvolvidos possibilitam uma melhor compreensão dos mecanismos de transporte, além de reduzir os esforços exigidos pelos modelos analíticos.

Nesse contexto, o MODFLOW e o MT3D têm sido amplamente utilizados nos últimos anos para entender o comportamento do fluxo das águas subterrâneas e o transporte de solutos em aquíferos (MENDONCA et al., 2005; FRANCA et al., 2006; DAHRI et al., 2011; FAKHARINIA; LALEHZARI; YAGHOOBZADEH, 2012; SAMHAN \& GHANEM, 2012). No entanto, a caracterização das propriedades hidrogeológicas dos aquíferos é fator importante nessa compreensão.

Neste trabalho, foi utilizado o modelo de transporte tridimensional MT3D para investigar os impactos sofridos pelo aquífero Rio da Batateira devido a níveis elevados de contaminação por esgoto urbano no Riacho dos Macacos, localizado na área de uma bateria de poços do sistema de abastecimento do município de Juazeiro do Norte, no Ceará. O traçador de contaminação utilizado foi o cloreto, por ser conservativo num sistema aquífero e apresentar concentrações relativamente elevadas em águas de poços que explotam o aquífero que é naturalmente pouco salinizado.

\section{METODOLOGIA}

\section{Área de estudo}

A bateria de poços do sistema de abastecimento do município de Juazeiro do Norte (Figura 1), localizada às margens do Riacho dos Macacos, encontra-se na Bacia Sedimentar do Araripe, onde os recursos hídricos subterrâneos são uma das mais importantes fontes de água potável para abastecimento público e privado. Nesta área aflora a formação Rio da Batateira, composta basicamente de arenitos de granulometria fina e grosseira, avermelhados e pardacentos, com intercalações de lentes de argila e folhelho. Estes arenitos são limitados na base por níveis de folhelho negro e marrom, às vezes betuminosos (DNPM, 1996).

A bateria de poços é constituída por 17 poços tubulares, sob gerenciamento da Companhia de Água e Esgoto do Ceará (CAGECE). A produção máxima atual da bateria, segundo a CAGECE, é de $2.592 \mathrm{~m}^{3} \cdot \mathrm{h}^{-1}$ com os poços bombeando 24 h.d $\mathrm{d}^{-1}$. Os filtros dos poços penetram somente o aquífero Rio da Batateira e o poço mais profundo (PT-06) possui $200 \mathrm{~m}$ de profundidade.

O perfil estratigráfico da área, obtido através dos perfis geológicos dos poços, indica que a formação Rio da Batateira apresenta espessura média de $114 \pm 15 \mathrm{~m}$ na área urbana, e de $145 \pm 33 \mathrm{~m}$ na área do Riacho dos Macacos (MENDONÇA et al., 2005).

$\mathrm{O}$ aquífero explotado é de boa produtividade, com rebaixamentos específicos nos poços variando de 1,7 a $21,7 \mathrm{~m}^{3} \cdot \mathrm{h}^{-1} \cdot \mathrm{m}^{-1}$, com média de $8,3 \pm 5,3 \mathrm{~m}^{3} \cdot \mathrm{h}^{-1} \cdot \mathrm{m}^{-1}$ (CAGECE, 1988). As águas subterrâneas nas proximidades da bateria de poços apresentam escoamento em direção ao Rio Batateira, com gradiente hidráulico médio de 4\%o (MENDONÇA et al., 2005).

De acordo com o Instituto Brasileiro de Geografia e Estatística (IBGE, 2010), o município de Juazeiro do Norte possui área territorial de apenas $249 \mathrm{~km}^{2}$ e uma população de aproximadamente 245.000 habitantes, com aproximadamente 95\% residindo em área urbana. Por causa de peregrinações, a população da cidade chega a triplicar algumas vezes no ano.

Nesta região, as temperaturas médias anuais variam de 25 a $30^{\circ} \mathrm{C}$, e a precipitação média é de aproximadamente $1.000 \mathrm{~mm} . \mathrm{ano}^{-1}$, comparável com a precipitação média na costa do Estado. Segundo a classificação de Köppen, o clima da região é do tipo tropical úmido com uma estação chuvosa. A vegetação na área é do tipo caatinga arbórea e mata seca. 


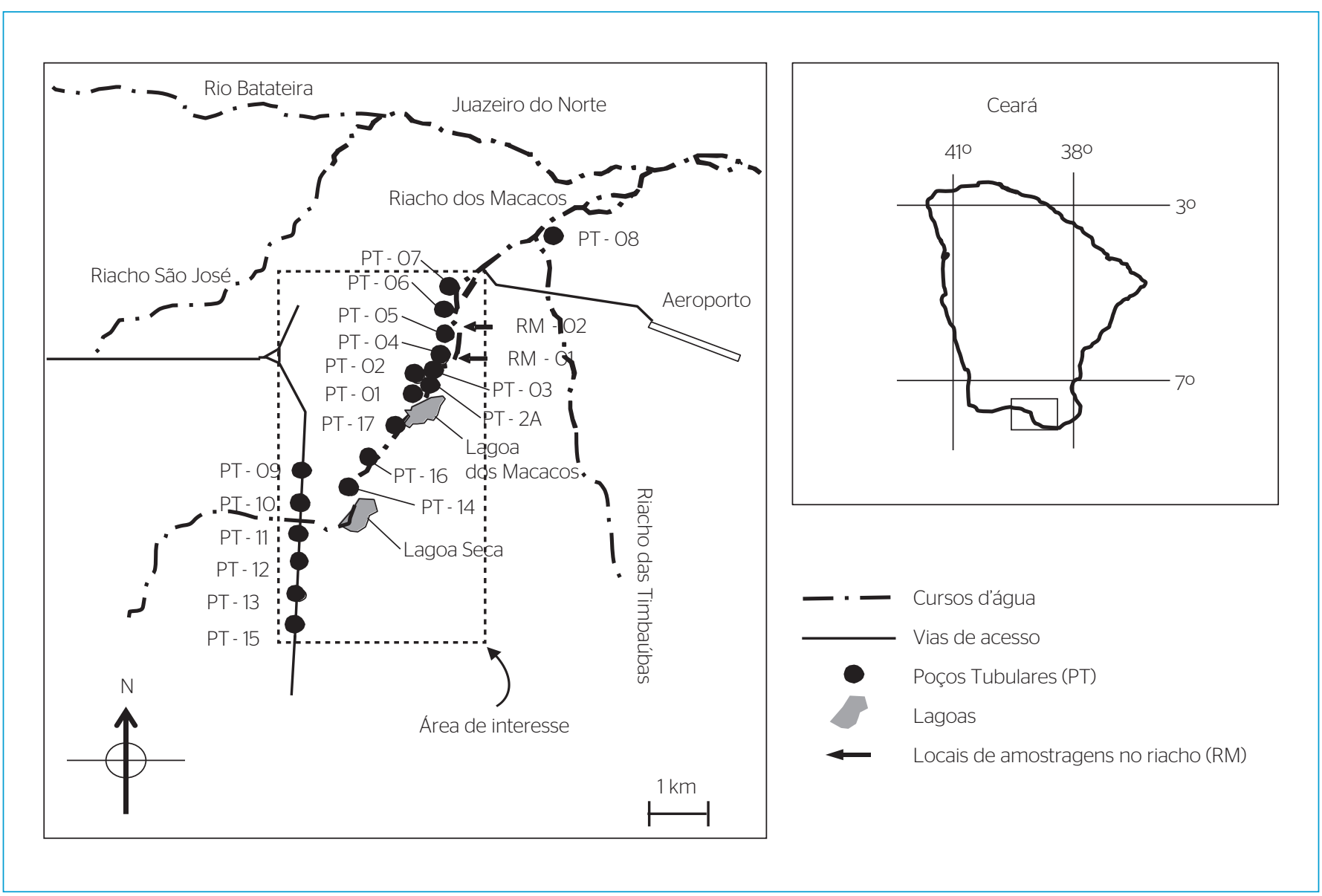

Figura 1 - Área de estudo.

\section{Modelos numéricos utilizados}

A equação diferencial parcial que descreve o movimento tridimensional da água através de um meio poroso, heterogêneo, anisotrópico e em estado transiente (obtida da combinação da Lei de Darcy com a equação da continuidade) é dada pela Equação 1 .

$\frac{\partial}{\partial x_{i}}\left[k_{i i} \frac{\partial h}{\partial x_{i}}\right]+q_{s}=S s \frac{\partial h}{\partial t}$

na qual:

$\mathrm{k}_{\mathrm{ii}}$ : componente principal do tensor condutividade hidráulica $\left[\mathrm{LT}^{-1}\right]$; h: carga hidráulica [L];

$\mathrm{q}_{\mathrm{s}}$ : vazão por unidade de volume representando fonte ou sumidouro $\left[\mathrm{T}^{-1}\right]$; Ss: armazenamento específico do material poroso $\left[\mathrm{L}^{-1}\right]$.

No MODFLOW a Equação 1 é aplicada a cada célula da malha de diferenças finitas, onde o fluxo interno através das faces da célula é descrito pela Lei de Darcy e o fluxo externo, por condições de contorno que determinam funções que formulam coeficientes que representam fonte e/ou sumidouro.
Enquanto o fluxo da água subterrânea é regido pela lei de Darcy, o transporte de soluto em meio poroso é controlado por diversos mecanismos: advecção ou convecção, dispersão hidrodinâmica, reações químicas e fenômenos de decaimento. Esses mecanismos podem ser caracterizados como fenômenos fonte-sumidouro para o soluto. Assim, a equação diferencial parcial que descreve o transporte tridimensional de contaminantes em águas subterrâneas é dada pela Equação 2.

$\frac{\partial\left(\theta \mathrm{C}^{\mathrm{k}}\right)}{\partial \mathrm{t}}=\frac{\partial}{\partial \mathrm{x}_{\mathrm{i}}}\left(\theta \mathrm{D}_{\mathrm{ij}} \frac{\partial \mathrm{C}^{\mathrm{k}}}{\partial \mathrm{x}_{\mathrm{j}}}\right)-\frac{\partial}{\partial \mathrm{x}_{\mathrm{i}}}\left(\theta \mathrm{v}_{\mathrm{i}} \mathrm{C}^{\mathrm{k}}\right)+\mathrm{q}_{\mathrm{s}} \mathrm{C}_{\mathrm{s}}^{\mathrm{k}}+\sum \mathrm{R}_{\mathrm{n}}$

na qual:

$\theta$ : porosidade efetiva do meio;

$\mathrm{C}^{\mathrm{k}}$ : concentração da espécie $\mathrm{k}$ na fase dissolvida $\left[\mathrm{ML}^{-3}\right]$;

$\mathrm{x}_{\mathrm{i}, \mathrm{j}}$ : direção ao longo da respectiva coordenada cartesiana [L];

$\mathrm{D}_{\mathrm{ij}}$ : tensor de dispersão hidrodinâmica $\left[\mathrm{LT}^{-1}\right]$;

$\mathrm{v}_{\mathrm{i}}$ : velocidade de percolação[ $\left[\mathrm{LT}^{-1}\right]$;

$\mathrm{q}_{\mathrm{s}}$ : vazão por unidade de volume representando injeção ou bombeamento $\left[\mathrm{T}^{-1}\right]$; $\mathrm{C}_{\mathrm{S}}^{\mathrm{K}}$ : concentração do componente $\mathrm{k}$ no fluxo de injeção ou de bombeamento $\left[\mathrm{ML}^{-3}\right]$;

$\sum \mathrm{R}_{\mathrm{n}}$ : termo de reação química $\left[\mathrm{ML}^{-3} \mathrm{~T}^{-1}\right]$. 
$\mathrm{Na}$ Equação 2, o $1^{\circ}$ termo da direita considera a dispersão do contaminante; o $2^{\circ}$, a advecção; o $3^{\circ}$, as fontes ou sumidouros; e o $4^{\circ}$, as reações químicas. $\mathrm{O}$ termo de reações químicas inclui reações bioquímicas e geoquímicas do transporte de contaminantes, considerando a sorção e a taxa de reação de primeira ordem. O termo de fontes ou sumidouros representa a massa de soluto que entra ou que sai do domínio do modelo. O termo de advecção representa o transporte de contaminantes miscíveis, com a mesma velocidade da água subterrânea. O termo de dispersão do contaminante representa o efeito combinado da dispersão mecânica e da difusão iônica. A dispersão mecânica origina-se do movimento proporcionado por variações na velocidade de percolação da solução entre poros de diferentes tamanhos, formas e direções. Já a difusão iônica origina-se da existência de gradientes de concentração (ZHENG \& GORELICK, 2003).

Nesse contexto, o modelo de transporte tridimensional MT3D soluciona a Equação 2 por diferenças finitas. Entretanto, as cargas hidráulicas e velocidades de percolação utilizadas na solução da Equação 2 são calculadas por simulação prévia do MODFLOW, que soluciona a Equação 1 também por diferenças finitas.

Neste trabalho, o cloreto é considerado elemento estável e conservativo devido à sua baixa reatividade e capacidade de adsorção. Assim, o termo que representa as reações químicas na Equação 2 será desprezado.

\section{Condições de contorno}

As condições de contorno utilizadas no modelo de fluxo foram:

- do tipo 1 ou Dirichlet, representado por cargas constantes especificadas no extremo superior e inferior do domínio do modelo, com valores iguais às cotas da superfície do nível estático, capazes de manter o gradiente hidráulico da região;

- do tipo 2 ou Neuman, representado pela recarga média anual do aquífero, proveniente da chuva e do riacho perenizado pelo esgoto, e pelos poços da bateria, com seus respectivos intervalos de filtros, vazões de bombeamento e raios.

Para o modelo de transporte, utilizou-se a condição de contorno do tipo 3 ou Cauchy, representada pela concentração do soluto na recarga proveniente do riacho.

\section{Coleta de dados e determinação de parâmetros do aquífero}

Para a construção do modelo de fluxo foi necessário conhecer: (i) o perfil estratigráfico do aquífero, obtido por Mendonça et al. (2005) a partir dos perfis geológicos dos poços; (ii) as superfícies topográfica, freática e da base do aquífero, obtidas com o programa SURFER, a partir de um banco de dados de poços fornecido pela Companhia de Gestão dos Recursos Hídricos do Estado do Ceará; (iii) os parâmetros hidrogeológicos do aquífero, determinados através dos modelos analíticos de Jacob, para aquífero confinado e de Neumann, para aquífero livre; (iv) os níveis dinâmicos e vazões de explotação dos poços, obtidos do relatório de testes de aquífero realizado pela CAGECE; (v) a recarga na área, estimada por Mendonça et al. (2005). Os tópicos (i) e (ii) foram utilizados na definição e discretização da malha de diferenças finitas.

Os dados dos poços da bateria utilizados no modelo de fluxo estão na Tabela 1.

Para a simulação da migração da pluma de poluição foi necessário conhecer: (i) as concentrações de cloreto nas águas subterrâneas e nas águas do riacho, obtidas de Franca et al. (2006); (ii) a recarga do aquífero proveniente do riacho, obtida na calibração transiente do modelo.

As concentrações de cloretos obtidas durante o monitoramento de poços e do Riacho dos Macacos estão na Tabela 2.

\section{RESULTADOS E DISCUSSÃO}

\section{Definição e discretização da malha de diferenças finitas}

O domínio do modelo, de extensão $11.000 \mathrm{~m}$ x $13.000 \mathrm{~m}$, foi escolhido de tal forma que a área de interesse, de aproximadamente $3.000 \mathrm{~m}$ x $6.000 \mathrm{~m}$ (Figura 1), correspondente à bateria de poços, ficasse centrada na malha.

Para entrada de dados no MODFLOW foi criada uma malha preliminar de 100 linhas, 100 colunas e 3 camadas, alinhada na direção geral do fluxo subterrâneo, que é para o Rio Batateira. Essa malha foi refinada horizontalmente em torno da bateria de poços para melhorar a definição dos rebaixamentos da superfície potenciométrica. Esse refinamento foi feito de modo que as distâncias entre linhas adjacentes não excedessem um fator de dois. Para diminuir o esforço computacional, uma vez que o número de equações a serem resolvidas depende do número de linhas, colunas e camadas, aumentou-se a dimensão horizontal das células nas regiões distantes da bateria. Desta forma, a dimensão horizontal de cada célula em torno da bateria de poços, após o refinamento, passou a ser $54,8 \mathrm{~m}$ por $53,2 \mathrm{~m}$ e nas regiões distantes da bateria, $252,5 \mathrm{~m}$ por $219,2 \mathrm{~m}$. As camadas verticais foram de dimensões variadas, definidas através da superfície topográfica, representando o topo da camada superior e da superfície da camada argilosa que limita o aquífero explotado, obtida a partir da profundidade dos poços, representando a base da camada inferior (Figura 2). A partir dos níveis estáticos dos poços foi definida a superfície piezométrica inicial, que apresentou um gradiente hidráulico médio de $4 \%$ na direção do fluxo, como proposto por Mendonça et al. (2005).

\section{Determinação de parâmetros hidrogeológicos do aquífero}

Os parâmetros coeficiente de armazenamento (S) e condutividade hidráulica (k) foram obtidos da interpretação de dois testes de aquífero, 
Tabela 1 - Características dos poços da bateria de Juazeiro do Norte, Ceará.

\begin{tabular}{|c|c|c|c|c|c|c|c|c|}
\hline Poço & \multicolumn{2}{|c|}{ Coordenadas UTM (m) } & $\mathrm{CT}(\mathrm{m})$ & $\operatorname{TF}(\mathrm{m})$ & $\mathrm{NE}(\mathrm{m})$ & $\mathrm{ND}(\mathrm{m})$ & $\mathrm{r} \times 10^{-3}(\mathrm{~m})$ & $Q\left(m^{3} \cdot h^{-1}\right), P-01$ \\
\hline P-O2 & 466028 & 9201040 & 414 & 58,6 & 7,7 & 27,3 & 76 & 120 \\
\hline$P-2 A$ & 466036 & 9201110 & 410 & - & - & - & - & 50 \\
\hline P-O3 & 466232 & 9201246 & 413 & 51,1 & 2,5 & 21,1 & 76 & 120 \\
\hline P-O4 & 461723 & 9200116 & 393 & 55,9 & $+1,4$ & 23,4 & 76 & 144 \\
\hline P-06 & 466375 & 9202231 & 390 & 87,9 & $+2,9$ & 25,4 & 76 & 144 \\
\hline P-O7 & 466272 & 9202632 & 393 & 51,4 & $+1,6$ & 27,6 & 76 & 120 \\
\hline P-16 & 465452 & 9199610 & 435 & 48,3 & 4,7 & 13,9 & 76 & 198 \\
\hline$P-17$ & 465719 & 9199971 & 409 & 39,8 & 1,4 & 13,1 & 127 & 214 \\
\hline$P-11$ & 464328 & 9198724 & 424 & 56,1 & 10,5 & 20,4 & 76 & 66 \\
\hline$P-12$ & 464333 & 9198328 & 428 & 61,8 & 15,4 & 25,3 & 76 & 113 \\
\hline P-13 & 464327 & 9197879 & 443 & 57,2 & 12,3 & 23,3 & 76 & 59 \\
\hline P-14 & 464943 & 9199246 & 432 & 67,5 & 8,9 & 20,4 & 76 & 158 \\
\hline P-15 & 464415 & 9197262 & 425 & 52,3 & 14,6 & 28,8 & 76 & 88 \\
\hline
\end{tabular}

Coordenadas UTM: zona 24S, SAD-69 datum; CT: cota topográfica; TF: topo do filtro; NE: nível estático; ND: hível dinâmico após 24 h de bombeamento; r: raio do poço; Q: vazão; +: nível estático jorrante.

Tabela 2 - Concentração de cloretos nas águas de poços e do Riacho dos Macacos, nos períodos seco e chuvoso.

\begin{tabular}{|c|c|c|c|c|c|c|c|}
\hline \multirow{3}{*}{$\begin{array}{l}\text { Pontos } \\
\text { de coleta }\end{array}$} & \multicolumn{7}{|c|}{ Concentração de cloretos (mg. $\mathrm{L}^{-1}$ ) } \\
\hline & \multicolumn{3}{|c|}{ Período seco } & \multicolumn{3}{|c|}{ Período chuvoso } & \multirow{2}{*}{ Média em todo período } \\
\hline & $20 / 06 / 02$ & $05 / 11 / 02$ & $10 / 12 / 02$ & $15 / 01 / 03$ & $25 / 04 / 03$ & $20 / 05 / 03$ & \\
\hline PT-01 & 19,5 & 18,9 & 20,8 & 30,4 & 21,7 & 18,7 & 21,6 \\
\hline PT-O2 & 36,0 & 30,2 & 36,5 & 35,2 & 23,9 & 38,7 & 33,4 \\
\hline PT-O3 & 36,0 & 28,2 & 31,9 & 39,5 & 34,9 & 32,5 & 33,8 \\
\hline PT-04 & 24,3 & 16,5 & 48,7 & 39,8 & 44,1 & 64,2 & 39,5 \\
\hline PT-05 & 11,7 & 5,8 & 23,5 & 5,6 & 4,6 & 10,8 & 10,3 \\
\hline PT-06 & 17,5 & 17,8 & 23,1 & 35,5 & 19,7 & 21,0 & 21,9 \\
\hline
\end{tabular}

Fonte: Franca et al. (2006).

PT: poço tubular; RM: Riacho dos Macacos vizinho aos poços PT-03 e PT-05.

utilizando o método de Jacob. Os poços estudados possuem profundidades superiores a $100 \mathrm{~m}$ e explotam o aquífero confinado Rio da Batateira. Nos testes, os poços PT-02 e PT-05 foram bombeados com vazão de $144 \mathrm{~m}^{3} \cdot \mathrm{h}^{-1}$ durante $24 \mathrm{~h}$ e os rebaixamentos foram observados nos poços PT-01 e PT-04, respectivamente. Os poços observados PT-01 e PT-04 encontram-se distanciados a $342 \mathrm{~m}$ e a $326 \mathrm{~m}$ dos poços bombeados e os valores de $\mathrm{S}$ e $\mathrm{k}$ foram de respectivamente $1,77 \times 10^{-4} \mathrm{e}$
$2,9 \times 10^{-5} \mathrm{~m} \cdot \mathrm{s}^{-1}$, e $2,71 \times 10^{-4}$ e 2,3 $\times 10^{-5} \cdot \mathrm{m} \cdot \mathrm{s}^{-1}$. Observa-se nesses dados que o aquífero pode ser considerado homogêneo, entretanto será considerado um modelo de transporte 3D para simulação da pluma de poluição nas direções horizontal e vertical.

A produção específica $\left(S_{y}\right)$ foi obtida através da interpretação de um teste de aquífero, utilizando o método de Neumann. No teste, o poço PT-01 foi bombeado com vazão de $102 \mathrm{~m}^{3} \cdot \mathrm{h}^{-1}$ durante $24 \mathrm{~h}$ e os 
rebaixamentos foram observados no poço PT-04 antigo, de $50 \mathrm{~m}$ de profundidade, perfurado na porção livre do aquífero Rio da Batateira. O poço observado encontra-se a $13 \mathrm{~m}$ do poço bombeado e o valor de $\mathrm{S}_{\mathrm{y}}$ foi de $20 \%$. Ainda nesse teste obteve-se k de 2,6 x 10 $10^{-5} \cdot \mathrm{m} \cdot \mathrm{s}^{-1}$.

Também foram interpretadas curvas de rebaixamentos com observação no próprio poço bombeado, utilizando o método de Jacob. Nos poços PT-01 a PT-07 e PT-15, os valores de k mantiveram-se na mesma ordem de grandeza dos testes observados em poços vizinhos, apresentando média de $3,0 \times 10^{-5} \mathrm{~m} \cdot \mathrm{s}^{-1}$ e desvio padrão de $0,7 \mathrm{x}$ $10^{-5} \mathrm{~m} . \mathrm{s}^{-1}$. Os poços PT-09 a PT-14, PT-16 e PT-17 apresentaram média de $8,6 \times 10^{-5} \mathrm{~m} \cdot \mathrm{s}^{-1}$ e desvio padrão de $2,8 \times 10^{-5} \mathrm{~m} \cdot \mathrm{s}^{-1}$.

\section{Solução do modelo de fluxo}

Na calibração transiente do modelo de fluxo, as cargas calculadas foram ajustadas às observadas, obtidas por testes de bombeamento com duração máxima de 24 h em cada poço.

O meio poroso foi considerado homogêneo e isotrópico, com discretização de k na região da bateria de poços. Em todo o domínio do modelo foi adotado coeficiente de armazenamento específico $\mathrm{S}_{\mathrm{S}}$ médio de $2 \times 10^{-6} \mathrm{~m}^{-1}$ (considerando a espessura média do aquífero de $112 \mathrm{~m}$ ) e $\mathrm{S}_{\mathrm{y}}$ de $20 \%$. Os valores de $\mathrm{k}$ foram ajustados durante a calibração do

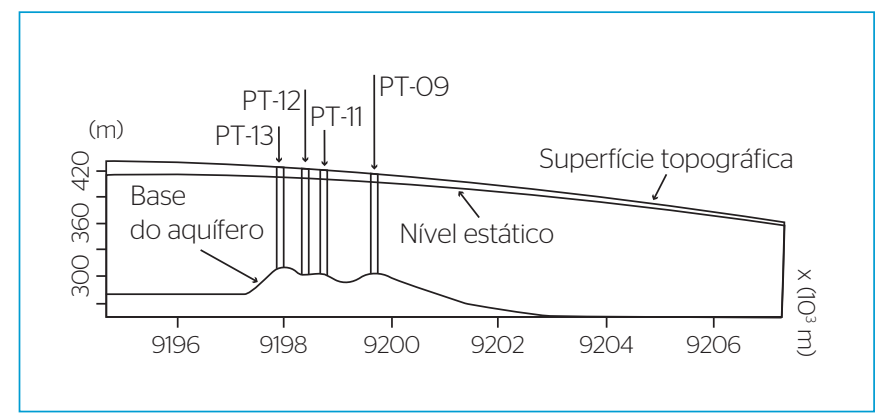

Figura 2 - Seção transversal ao longo de uma coluna da malha de diferenças finitas, indicando o topo, o nível estático e a base do aquífero. modelo, permanecendo na mesma ordem de grandeza dos obtidos nos testes de bombeamento. $\mathrm{O}$ k ajustado apresentou média e desvio padrão de respectivamente $2,7 \times 10^{-5} \mathrm{~m} \cdot \mathrm{s}^{-1} \mathrm{e} 0,2 \times 10^{-5} \mathrm{~m} \cdot \mathrm{s}^{-1}$, para os

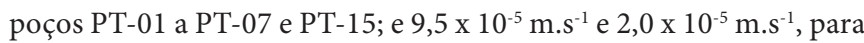
os poços PT-09 a PT-14, PT-16 e PT-17. No ajuste das cargas dos poços PT-05 e PT-09 a PT-17, foi necessário adotar para a segunda camada, em torno dos poços, uma condutividade hidráulica da ordem de $10^{-9} \mathrm{~m} \cdot \mathrm{s}^{-1}$, representando os folhelhos encontrados no perfil estratigráfico proposto por Mendonça et al. (2005).

Todos os poços apresentaram um bom ajuste das cargas no final do bombeamento. Apenas os poços PT-04, PT-05 e PT-06 apresentaram desvios consideráveis no início do bombeamento (Figura 3). Esses poços estão localizados nas proximidades de uma descontinuidade na camada argilosa da base do aquífero. Essa descontinuidade, identificada por Mendonça et al. (2005), propicia o surgimento de um fluxo ascendente, proveniente do aquífero confinado mais profundo, contribuindo com a redução do rebaixamento no início do bombeamento desses poços. Esse efeito não foi observado nesta simulação porque o modelo aqui proposto só considera o aquífero Rio da Batateira, além do mais, esse efeito só se torna mais evidente quando os referidos poços são utilizados apenas como poços de observação.

O gráfico das cargas hidráulicas observadas versus calculadas, de todos os poços e a estatística de erros fornecida pelo modelo encontra-se na Figura 4A. Os resultados indicam um bom ajuste entre os valores calculados e observados, com erro quadrático médio de $0,52 \mathrm{~m}$ e erros médio e médio absoluto de respectivamente 0,0037 e 0,44 m.

Após a calibração do modelo, foi realizada uma simulação de 365 dias de explotação com todos os poços da bateria bombeando com vazão máxima. Nessa simulação, foram adotadas as condições de contorno: cargas fixas iguais às cotas da superfície do nível estático nos extremos superior e inferior do domínio do modelo; e recarga de $8 \mathrm{~mm} / \mathrm{ano}$, correspondendo à média anual para áreas desmatadas no topo da Chapada do Araripe, proposta por Mendonça et al. (2005). A evapotranspiração
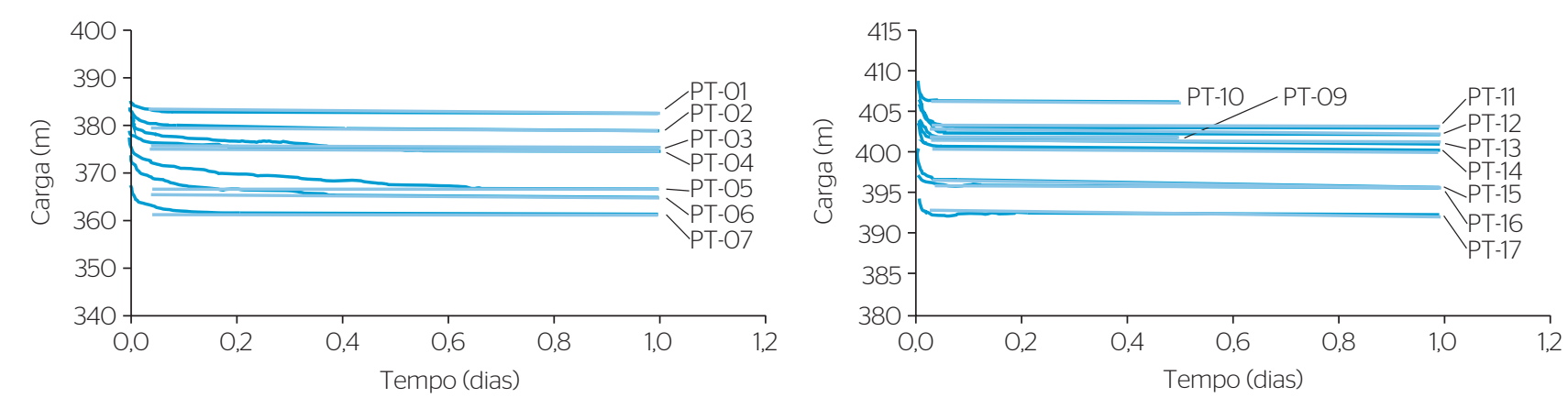

- Observado Calculado

Figura 3 - Ajuste das cargas hidráulicas nos poços. 
foi negligenciada, já que o nível dinâmico encontra-se muito profundo na área de interesse. A Figura 4B mostra as linhas equipotenciais das cargas e os rebaixamentos calculados.

De acordo com a Figura 4B, o rebaixamento dos poços às margens do Riacho dos Macacos chega a 18 m e o cone de depressão atinge uma largura máxima de aproximadamente $4,5 \mathrm{~km}$ e um comprimento aproximado de $8,0 \mathrm{~km}$. Fazendo uma análise do rebaixamento, observa-se uma maior exploração do aquífero na região dos poços às margens do Riacho dos Macacos.

Nesta simulação, a velocidade máxima do fluxo, calculada pelo MODFLOW, foi de $1,9 \times 10^{-5} \mathrm{~m} . \mathrm{s}^{-1}$. Esse valor situa-se na faixa dos valores encontrados na literatura, para aquíferos compostos por arenitos com presença de argila (GELHAR; WELTY; REHFELDT, 1992).

\section{Solução do modelo de transporte}

A calibração transiente do modelo de transporte foi feita com base no ajuste das concentrações de cloretos calculadas pelo MT3D com as médias obtidas de Franca et al. (2006) nas águas dos poços próximos ao riacho poluído.

A concentração natural de cloretos adotada para toda a área de domínio do modelo foi de $10 \mathrm{mg} . \mathrm{L}^{-1}$ e representa a média dos valores mínimos observados nos poços da bateria, distantes da fonte poluidora.
No modelo de fluxo, admitiu-se uma recarga através do Riacho dos Macacos, cujo valor inicial foi de $1.000 \mathrm{~mm} . \mathrm{ano}^{-1}$. Esse valor foi modificado durante a calibração para ajustar as concentrações de cloretos calculadas. A concentração de cloretos na recarga proveniente do riacho foi a média dos valores obtidos por Franca et al. (2006), em dois pontos de coleta no próprio riacho (RM-01 e RM-02 na Figura 1).

De acordo com Franca et al. (2006), a concentração de cloretos no riacho não é uniforme. Na região do riacho próxima ao poço PT-03 há uma entrada maior de esgoto, enquanto que próximo ao poço PT-05 a topografia é rebaixada, com área alagada, onde o esgoto está mais diluído. Com essa informação e por falta de mais dados de concentrações ao longo do riacho, consideraram-se, na condição de contorno concentração da recarga, $280 \mathrm{mg} . \mathrm{L}^{-1}$ a montante do poço PT 04 e $75 \mathrm{mg} . \mathrm{L}^{-1}$ a jusante.

Os coeficientes de dispersão foram atribuídos considerando o perfil estratigráfico do aquífero Rio da Batateira proposto por Mendonça et al. (2005), composto de arenito, arenito argiloso e argila. Nesse contexto, atribuiu-se dispersividade longitudinal de $1,00 \mathrm{~m}$, transversal de $0,10 \mathrm{~m}$ e vertical de $0,01 \mathrm{~m}$, a partir da literatura (GELHAR; WELTY; REHFELDT, 1992), considerando dados de aquíferos litologicamente semelhantes ao Rio da Batateira.
A

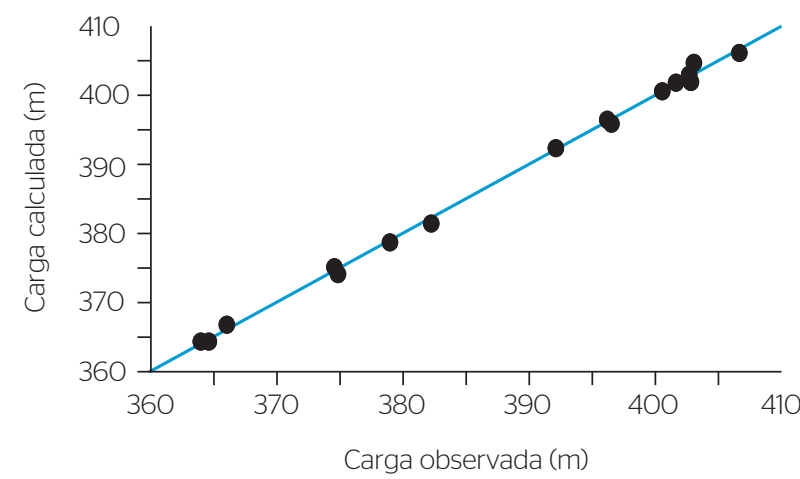

Erro médio: $3,7 \times 10^{-3}$

Erro médio absoluto: $4.4 \times 10^{-1}$

Erro quadrático médio: $5,2 \times 10^{-1}$
B

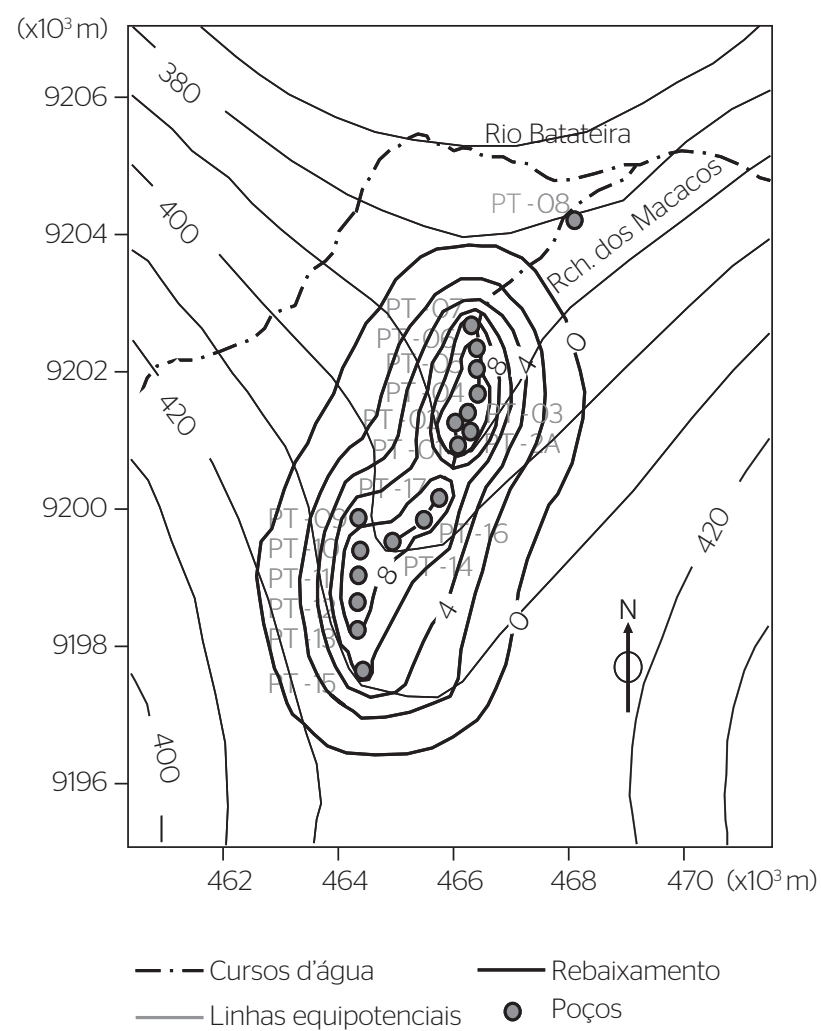

Figura 4 - Carga hidráulica calculada versus carga observada, estatística de erros (A) e linhas equipotenciais das cargas e rebaixamentos calculados pelo MODFLOW. 
O coeficiente de difusão utilizado foi de $10^{-9} \mathrm{~m}^{2} \cdot \mathrm{s}^{-1}$, proposto por Robinson e Stokes (1965), para íons mono e bivalentes em águas subterrâneas.

Fontes e sumidouros foram representados, respectivamente, pela recarga proveniente do riacho e pelo bombeamento dos poços.

A calibração do MT3D foi feita por meio do ajuste da concentração em cada poço, variando a recarga proveniente do riacho.

O gráfico das concentrações de cloretos calculadas versus observadas, para os poços monitorados PT-01 a PT-06, encontra-se na Figura 5A e mostra o ajuste obtido ao final da calibração e a estatística de erros fornecida pelo modelo.

A recarga atribuída ao longo do riacho para obter esse ajuste foi de $16.500 \mathrm{~mm}$ ano $^{-1}$. Esse valor de recarga está dentro da ordem de grandeza esperada, calculada a partir da lei de Darcy, considerando uma condutividade hidráulica de $10^{-6} \mathrm{~m} \cdot \mathrm{s}^{-1}$, para a camada argilosa superficial do aquífero e um gradiente de $1 \mathrm{~m} . \mathrm{m}^{-1}$, entre o nível da água no riacho e o nível dinâmico do aquífero.

Para o ajuste da concentração nos poços PT-2A, PT-05 e PT-06, foi necessário variar a concentração da recarga proveniente do riacho em torno do valor médio nas proximidades de tais poços.

A Figura 5B mostra a variação da concentração de cloreto em cada poço em função do tempo no período de monitoramento de 11 meses. Todos os poços localizam-se muito próximos do riacho, à máxima distância de $70 \mathrm{~m}$, o que faz com que o deslocamento da pluma seja induzido pelo bombeamento dos mesmos. A concentração de cloretos no poço PT-2A, por ser mais raso, é mais elevada. Além disso, depois de certo tempo, a concentração de cloretos nos poços tende a atingir um patamar por causa da mistura da água poluída, proveniente do riacho, com a água em condições naturais, proveniente do aquífero.

A concentração de cloretos no poço PT-05 permanece praticamente igual à concentração do aquífero, por possuir camadas de folhelhos acima dos filtros (representadas no modelo pela condutividade hidráulica de $10^{-9} \mathrm{~m} \cdot \mathrm{s}^{-1}$ ), protegendo o aquífero da propagação da pluma. Esse poço, de acordo com Mendonça et al. (2005), também recebe uma forte recarga por águas ascendentes, através de descontinuidades no confinamento inferior do aquífero.

A Figura 6A mostra a propagação horizontal da pluma de cloretos no período de 11 meses de simulação.

Como o transporte é predominantemente advectivo, a pluma de poluição se desloca lentamente, com uma velocidade da ordem de $10^{-5} \mathrm{~m} \cdot \mathrm{s}^{-1}$, e a direção predominante de propagação da pluma é induzida pelo bombeamento dos poços.

A Figura 6B mostra a propagação vertical da pluma nas proximidades do poço PT-04, onde se observa que a mesma não tem grande espalhamento horizontal. Isso ocorre porque os filtros dos poços estão localizados na parte mais profunda do aquífero.

Em um cenário de 5.000 dias, mantendo a recarga de concentração do riacho, observou-se que a pluma permanece na região da bateria, indicando que toda a poluição proveniente do riacho é captada pelos poços, não se propagando para outras áreas.

Com o objetivo de estimar em quanto tempo o aquífero se recuperaria, caso cessasse o lançamento de cloretos, fez-se uma simulação desativando a recarga proveniente do riacho após 330 dias de contaminação. A Figura 7 mostra o resultado para cada poço avaliado.
A

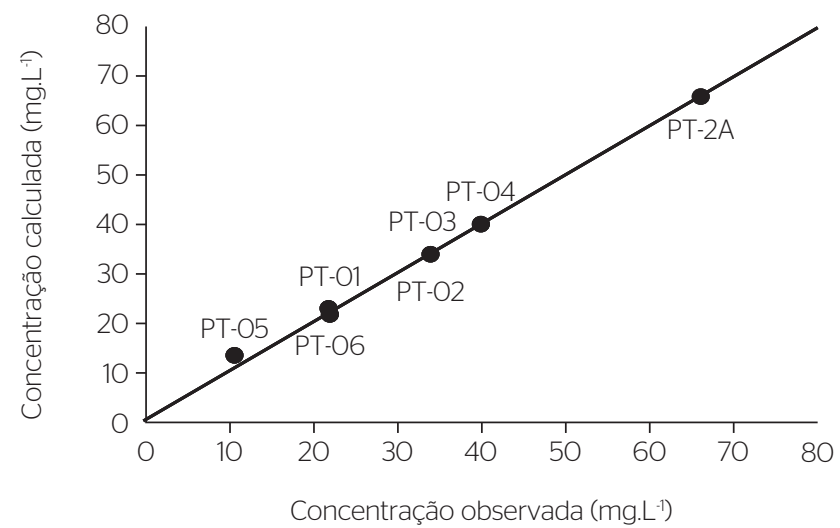

B

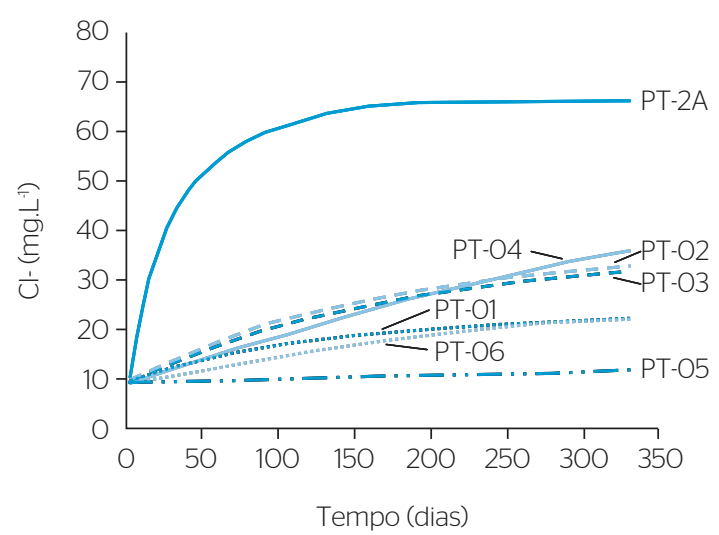

Erro médio: $1,5 \times 10^{-2}$

Erro médio absoluto: $5,4 \times 10^{-1}$

Erro quadrático médio: $6,9 \times 10^{-1}$

Figura 5 - Concentração de cloreto calculada versus observada, estatística de erros (A) e variação da concentração de cloreto com o tempo nos poços avaliados (B). 


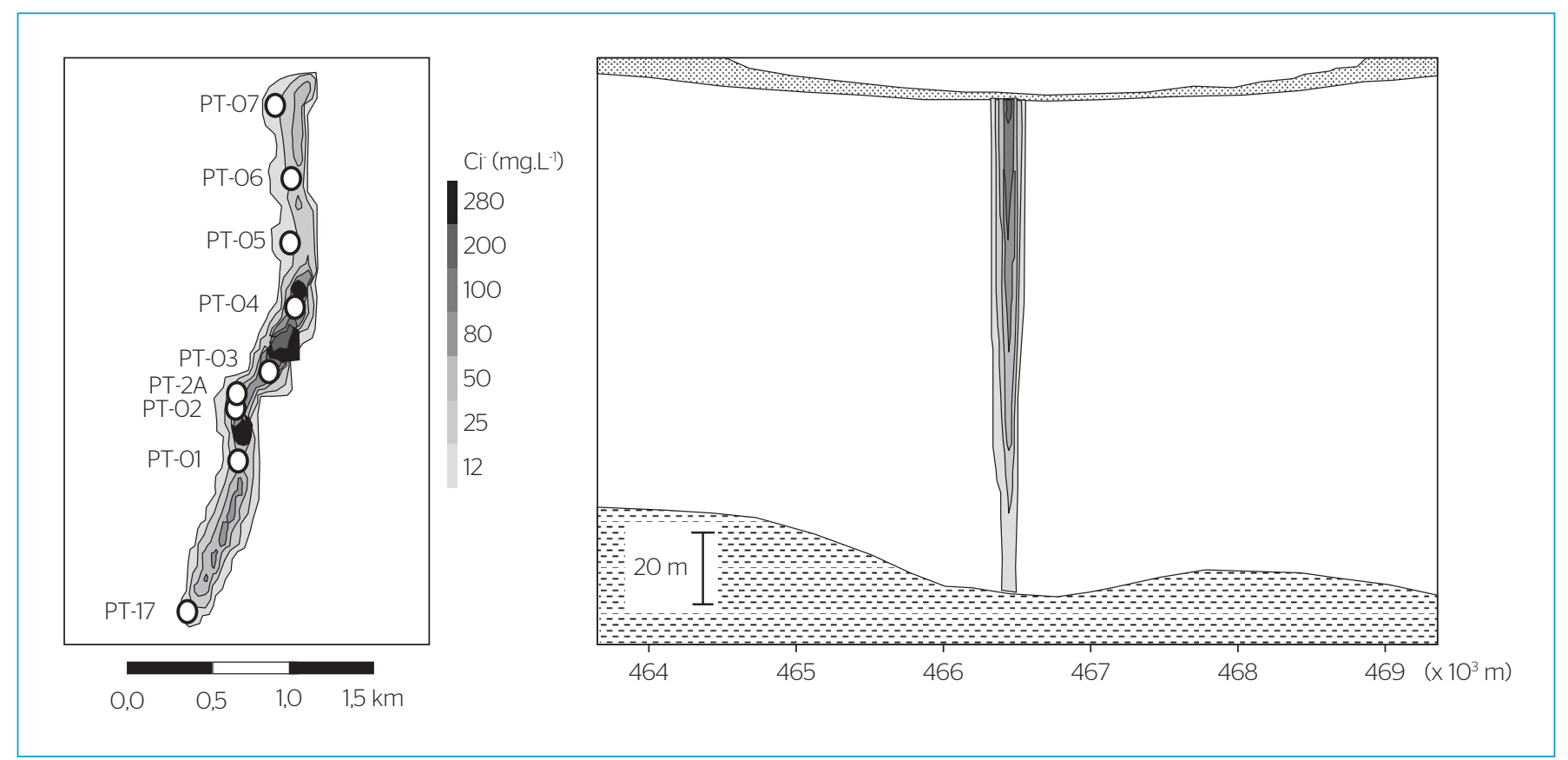

Figura 6 - Propagação horizontal (A) e vertical, em torno do poço PT-04 (B), da pluma de cloreto, durante um período de 11 meses.

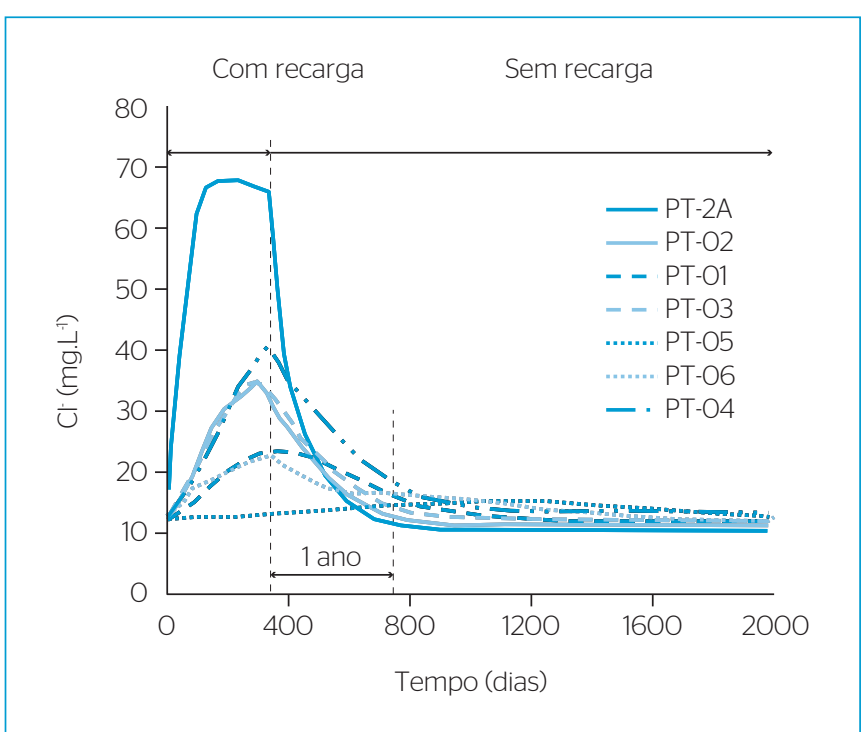

Figura 7 - Recuperação do aquífero após desativação da recarga com cloreto.

De acordo com a Figura 7, cerca de um ano após a recarga do riacho ter sido desativada, a concentração de cloretos volta aos níveis naturais no aquífero devido apenas ao bombeamento dos poços. Esse efeito se deve à condição do cloreto ser estável e conservativo, além das zonas aquíferas explotadas se encontrarem-se relativamente profundas, propiciando a captação de misturas entre as águas superficiais poluídas e as mais profundas, isentas de poluição. Essa mistura foi identificada e estudada por Mendonça et al. (2005).

\section{CONCLUSÕES}

Utilizando-se o MODFLOW, foi construído o modelo de fluxo tridimensional em uma porção do aquífero arenitico Rio da Batateira, tendo como área de interesse a bateria de poços que abastece a cidade de Juazeiro do Norte, no Ceará, construida às margens do Riacho dos Macacos. A calibração do modelo de fluxo, ajustando os parâmetros $\mathrm{k}$ e $\mathrm{S}_{\mathrm{S}}$ e comparando as cargas hidráulicas calculadas com as observadas em testes de bombeamento realizados em 16 poços tubulares, apresentou pouca discrepância, com erro quadrático médio de apenas $0,52 \mathrm{~m}$.

A modelagem de fluxo mostrou que os rebaixamentos produzidos pelo bombeamento da bateria de poços do sistema de abastecimento são maiores na região dos poços às margens do Riacho dos Macacos, pelo fato deles estarem mais próximos uns dos outros, ocasionando interferência dos poços por superposição dos cones de depressão.

Utilizando-se o MT3D, foi construído um modelo de transporte de soluto, utilizando o cloreto como traçador. A calibração do modelo de transporte, ajustando a recarga proveniente do Riacho dos Macacos e comparando as concentrações de cloretos calculadas com as observadas em campanhas de monitoramento realizadas em sete poços, apresentaram poucas discrepâncias, com erro quadrático médio de apenas $0,69 \mathrm{mg} \cdot \mathrm{L}^{-1}$.

A modelagem de transporte mostrou que a pluma de contaminante ocorre, predominantemente, na vertical, por causa da recarga proveniente do riacho poluído e do bombeamento dos poços, cujos filtros encontram-se a grandes profundidades, induzindo um fluxo descendente. Isso faz com que a pluma não se desloque para outras regiões do aquífero. 
Os resultados também mostraram que há um aumento gradual nas concentrações de cloretos nas águas explotadas e apenas o poço mais raso atingiu a concentração de cloreto do riacho em menos de 300 dias.

Em uma simulação futura observou-se que as concentrações de cloretos relativamente elevadas nas águas dos poços da bateria podem voltar aos valores naturais do aquífero em aproximadamente um ano, caso seja interrompido o lançamento de esgoto no riacho.
Assim o Riacho dos Macacos constitui o elo principal na conexão entre as águas superficiais poluídas e as águas subterrâneas, funcionando como fonte persistente e contínua de poluição, e necessita de elevada atenção e proteção.

Neste contexto, devem ser tomadas precauções para impedir a presença de esgoto e lixo na área, para evitar a infiltração de efluentes que poderão, no futuro, levar as comunidades que explotam o aquífero por poços mais rasos à calamidade sanitária.

\section{REFERÊNCIAS}

BATU, V. (1996) A generalized three-dimensional analytical solute transport model for multiple rectangular first-type sources. Journal of Hydrology, v. 174, n. 1-2, p. 57-82.

CAGECE - Companhia de Água e Esgotos do Ceará. (1988) Captação de Juazeiro do Norte: condição de explotação dos poços. Relatório de conclusão. Fortaleza, CE: CAGECE.

DAHRI, Z.H.; TARIQ, A.R.; AHMAD, B.; ALI, G.; AHMAD, S. (2O11) Numerical analysis of groundwater-flow and solute-transport under skimming Well. Science, Technology \& Development, v. 30, n. 1, p. 12-28.

DNPM - Departamento Nacional da Produção Mineral. (1996) Projeto de avaliação hidrogeológica da bacia sedimentar do Araripe. Recife: DNPM. 103 p.

FAKHARINIA, M., LALEHZARI, R.; YAGHOOBZADEH, M. (2012) The use of subsurface barriers in the sustainable management of groundwater resources. World Applied Sciences Journal, v. 19, n. 11, p. 1585-1590.

FRANCA, R.M.; FRISCHKORN, H.; SANTOS, M.R.P.; MENDONÇA, L.A.R. BESERRA, M.C. (2006) Contaminação de poços tubulares em Juazeiro do Norte-CE. Engenharia Sanitária e Ambiental, v. 11, n. 1, p. 92-102.

GELHAR, L.W.; WELTY, C.; REHFELDT, K.R. (1992) A critical review of data on field-scale dispersion in aquifers. Water Resources Research, v. 28, n. 7. p. 1955-1974.

HUYAKORN, P.S.; UNGS, M.J.; MULKEY, L.A.; SUDICKY, E.A. (1987) A three-dimensional analytical method for predicting leachate migration. Ground Water, v. 25, n. 5, p. 588-598.

IBGE - Instituto Brasileiro de Geografia e Estatística. (2010) Dados do censo 2010. Diário Oficial da União de 04/11/2010. Disponível em <http://www.bge. gov.br/censo2010/dados_divulgados/index.php>. Acesso em: 10 jan. 2011.

LEIJ, F.J.; SKAGGS. T.H.; VAN GENUCHTEN, M.T. (1991) Analytical solutions for solute transport in three-dimensional semi-infinite porous media. Water Resources Research, v. 27, n. 10, p. 2719-2733.

LINDSTROM, F.T \& BOERSMA, L. (1989) Two-dimensional transport and fate of chemicals emitted by arbitrarily placed sources in confined aquifers. Water Resources Research, v. 25, n. 7, p. 748-1756
MENDONÇA, L.A.R.; FRISCHKORN, H.; SANTIAGO, M.F.; MENDES FILHO, J. (2005) Isotope measurements and ground water flow modeling using MODFLOW for understanding environmental changes caused by a well field in semiarid Brazil. Environmental Geology, v. 47, n. 8, p. $1045-1053$

McDONALD, M.G. \& HARBAUGH, A.W. (1988) A modular threedimensional finite- difference groundwater flow model (MODFLOW) Washington: Techniques of Water Resources Investigations of the U.S. Geol. Survey. Book 6. 586 p.

ROBINSON, R.A. \& STOKES, R.H. (1965) Electrolyte Solutions. 2 ed. London: Ed. Butterworth.

SALCEDO-SÁNCHEZ, E.R.; ESTELLER, M.V.; HOYOS, S.E.G.; MARTÍNEZMORALES, M. (2013) Groundwater optimization model for sustainable management of the Valley of Puebla aquifer, Mexico. Environmental Earth Sciences, v. 70, p. 337-351.

SAMHAN, N. \& GHANEM, M. (2O12) Groundwater assessment for the NW of Auja Tamaseeh Basin in Tulkarem area, West Bank. Journal of Water Resource and Protection, v. 4, p. 407-413.

WILSON, J.L. \& MILLER, P.J. (1978) Two dimensional plume in uniform ground-water flow. Journal of the Hydraulics Division, v. 104, n. 4 , p. 503-514.

ZHENG, C. (1990) MT3D, a modular three-dimensional transport model for simulation of advection, dispersion and chemical reactions of contaminants in groundwater systems. Ada, OK: Report to the U.S. Environmental Protection Agency. $170 \mathrm{p}$

ZHENG, C. (2009) Recent developments and future directions for MT3DMS and related transport codes. Ground Water, v. 47, n. 5 , p. 620-625.

ZHENG, C. (2010) MT3DMS v5.3 Supplemental User's Guide. Tuscaloosa, Alabama: University of Alabama, Department of Geological Sciences. $50 \mathrm{p}$.

ZHENG, C. \& GORELICK, S.M. (2003) Analysis of solute transport in flow fields influenced by preferential flow paths at the decimeter scale. Ground Water, v. 41, n. 2, p. 142-155. 